\title{
Ova Fatty Acids Composition and Spawning Performances of Silver Carp, Hypophthalmichthys molitrix (Morocco)
}

\author{
Fatima-Zahra Majdoubi ${ }^{1,2,3, *} \mathbb{D}$, Redouane Benhima ${ }^{4}$, Anouar Ouizgane ${ }^{1}$, Sana \\ Farid $^{1}$, Mohammed Droussi ${ }^{5}$, Giulia Guerriero ${ }^{3, \#}$, Mustapha Hasnaoui ${ }^{1, \#}$
}

\author{
${ }^{1}$ Environmental Engineering Team. University of Sultan Moulay Slimane, Faculty of Sciences and Techniques BO. 523, \\ Beni Mellal, Morocco. \\ ${ }^{2}$ Deroua fish farm, Fkih Ben Saleh, Morocco. \\ ${ }^{3}$ EClab, Department of Biology, University of Naples "Federico II", Naples, Italy. \\ ${ }^{4}$ Laboratory of Biotechnology and Physiology of Plant, Faculty of Sciences, University Mohammed V, Rabat, 4 Avenue \\ Ibn Battouta, B.P. 1014 RP, Rabat, Morocco. \\ ${ }^{5}$ International aquaculture consultant, Beni-Mellal, Morocco. \\ \#These authors made equal contributions.
}

\section{Article History}

Received 26 June 2020

Accepted 30 October 2020

First Online 06 November 2020

\section{Corresponding Author \\ Tel.: +212663422090 \\ E-mail: f.zmajdoubi@gmail.com}

\section{Keywords}

Eggs

Silver carp

Fatty acids

Fertilization

Morocco

\begin{abstract}
The present study is performed in order to determine the relationship between fatty acid (FA) profile of silver carp (Hypophthalmichthys molitrix) eggs and fertilization success, embryos viability and larval production. Mature unfertilized ova were collected during the reproductive season from 23 mature and healthy females, reared in Deroua fish farm (Morocco). Total lipids were extracted from ova sample and subjected to trans-esterification then the resulting fatty acids methyl esters were analyzed by gas chromatography tandem mass spectrometry (GC/MS/MS). The results showed that silver carp ova are dominated on total FA by docosahexaenoic acid (DHA) (21.21\%) followed by oleic acid (21.07\%), palmitic acid (17.71\%) and eicosapentaenoic acid (EPA) (10.25\%). During the breeding season, polyunsaturateds (PUFAs), monounsaturateds (MUFAs) and saturated fatty acids (SFA) didn't show any significant difference. Moreover, within the PUFAs, the $n-3$ series were more abundant than the $\mathrm{n}-6$ series, the total mean was $31.57 \pm 1.01 \%$ and $5.33 \pm 0.32 \%$, respectively. No correlation was between fatty acids and the fertilization success. Maternal weight has effect on the levels of oleic acid (C18:1), arachidonic acid (C20:4) and docosahexaenoic acid (C22:6) in the egg whereas levels of palmetoleic acid (C16:1), eicosapentaenoic cid (C20:5) and docosahexaenoic acid (C22:6) are related to female age.
\end{abstract}

\section{Introduction}

In Morocco, more than 14 million of fish fry are dumped in water dams and $90 \%$ of this production is represented by silver carp (Hypophthalmichthys molitrix), the rest is represented by common carp (Cyprinus carpio), grass carp (Ctenopharyngodon idella), Northern pike (Esox lucius), and largemouth bass (Micropterus salmoides) (Laamiri, 2014). Silver carp was acclimatized for the first time in Morocco in the 1983 to enhance drinking water quality. Besides, along with other freshwater fish, it is designated to ensure high quality protein resources for the population living in the rural areas. For these reasons, culturists should improve their skill and practices in order to ensure sustainable supply of good quality seeds with optimal labor and production costs. To do so, scientists considered that the determination of biomarkers as indicators of the ova viability is a useful tool in aquaculture (da Silva et al., 2018). Determining the role, function and the mechanism of biochemical components in ova and their effect on the progeny will lead to optimize resources and to a better understanding of mechanisms that determine high egg and larvae quality (Tocher., 2003, Ye et al., 2019).

Lipids and their constituent fatty acids are, along with proteins, the major organic constituents of fish (Taşbozan and Gökçe, 2017 and González-Félix et al., 
2019). They are used for ova production, embryos and first stage of larval development. In general, lipid utilization in freshwater fish eggs can occur during the whole developmental stages including embryogenesis (Palacios et al., 2007). Moreover, catabolism of lipids results in the release of free fatty acids which can be used in several purposes. They have significant function in the success of the reproduction outcome of several animal species (e.g. ruminants, Mattos et al., 2000; pink shrimp, Emernciano et al., 2014; oysters, Bayne, 2017; Sprague Dawley rats, Ye et al., 2019). Concerning fish, many studies showed that there is some relationship between reproductive success and fatty acids composition. It was demonstrated that they are the major source of metabolic energy for reproduction and they are used for growth from the egg to the adult fish regulating the biophysical properties of cellular membranes (Bacle et al., 2020).

The eggs of most freshwater fish contain higher levels of n-6 PUFA, particularly 20:4n-6 and 18:2n-6 (Wiegand, 1996). As mentioned before, they are essential for the reproductive success of fish. To illustrate, PUFAs in common carp 'eggs (Cyprinus carpio) are very essential in terms of fertilization success and larval development (Mukhopadhyay and Ghosh, 2003). Also, a previous study performed on common snook (Centropomus undecimalis) proclaims that the success of fertilization and larval survival rate are related to high concentration of DHA in eggs (Yanes-Roca et al., 2009). Moreover, various studies proved that many egg quality criteria, including hatching and fertilization rates and early survival, were positively correlated with increased levels of n-3 HUFA, and interestingly, levels of 20:4n-6 of cod, Gadus morhua, sea bream, Sparus aurata, sea bass, Dicentrarchus labrax and in limbaugh's damselfish, Chromis limbaughi (Bruce et al., 1999; González-Félix et al., 2019). On the other hand, in freshwater fish it was found that balanced ratio of $n-3$ and $n-6$ fatty acids enhances the reproductive performances of zebrafish, Danio rerio, females and increases the hatching rate (Jaya-Ram et al., 2008). Furuita et al. (2007) showed that n-3 and n-6 fatty acids are necessary for Japanese eel, Anguilla japonica, reproduction but a high ratio affects negatively the embryos development. In addition, fatty acids impact significantly the eggs and larval quality in Eurasian perch, Perca fluviatilis, and common carp, Cyprinus carpio, (Mukhopadhyay et al., 2003; Henrotte et al., 2010).

Fatty acids composition in the eggs is related to many factors. The most important causes of the variation in the fatty acid profiles are the differences among species and the broodstock nutrition too since all nutrients needed during embryogenesis until the first exogenous feeding are provided maternally and transferred to the oocyte during vitellogenesis (Izquierdo et al., 2001; Grote et al., 2012; Asil et al., 2017; Taşbozan and Gökçe, 2017). For the European eel (Anguilla anguilla, L.), it was proved that fatty acids levels in fish body and tissues decreased during gametes maturation (sperm, Baeza et al., 2015 and Butts et al., 2015; oocytes, Nowosad et al., 2015). It was demonstrated that during the process of maturation of the European eel female's, docosahexaenoic acid (DHA) eicosapentaenoic acid (EPA) decreased in muscles and increased in ovaries (Nowosad et al., 2015). Further, Clevestam et al. (2011) reported that deficient fat reserves in European eel body could prevent oocytes maturation and the production of good quality eggs.

It was also found that fatty acids profile in eggs differ between captive and wild fish (Salze et al., 2005; Palacios et al., 2007; Seaborn et al., 2009; Lanes et al., 2012). Therefore, it has been reported that environmental conditions have significant impact on the biochemical composition of fish eggs (Krautz et al., 2010). Castro et al., (2010) revealed that eggs collected from cold water contained higher PUFA while eggs collected from warm waters contained higher MUFA. Moreover, it was showed in other studies that species and stock differences influence the variability of fatty acids in fish eggs (Pickova et al., 1997).

The present study aims to determine the variability intra spawning of fatty acids profile in ova collected from silver carp (Hypophthalmichthys molitrix), reared in Morocco at Deroua fish farm. It investigates the relationship between these fatty acids and the fertilization success and embryos survival. In particular, it examines the effects of maternal age and weight on the fatty acid's composition in the unfertilized eggs.

\section{Materials and Methods}

\section{Ethics Statement}

The species examined is considered as invasive species in the international species catalogue, including the CITES list (www.cites.org). Our experiments were performed in strict accordance with European (Directive 2010/63) legislation on the care and use of animals for scientific purpose.

\section{Ova Sampling}

The collection of ova was done in April 15th and May15th, in the spawning period. Broodstock are originated from Deroua Fisheries Station located in semi-arid climate zone in Morocco. They were held in earthen ponds and fed with phytoplankton present naturally in these ponds along grounded fish meal sprayed on water surface (Farid et al., 2017). The artificial breeding of silver carp was performed according to the method of Horvath et al (2015). The breeding season in morocco, which is classified in arid and semi-arid zones, starts from April and extends to June when water temperature in ponds varies between $20^{\circ} \mathrm{C}$ and $26^{\circ} \mathrm{C}$. Broodstock selection and harvesting was performed smoothly in order to avoid fish stress. mature and healthy fish are transferred to the hatchery and kept in tanks where the water temperature is $24^{\circ} \mathrm{C}$. the males 
and females were kept in tanks separately. After weighting and color marking in the dorsal fin, they are gently injected by common carp pituitary homogenate (CPH) to induce ovulation for females and spermiation for males. Females receive a first injection at a rate of $0.3 \mathrm{mg} / \mathrm{kg}$ of their weight, 12 hours later they receive a second injection at a rate of $3 \mathrm{mg} / \mathrm{kg}$ of their weight. Males receive a single injection of $3 \mathrm{mg} / \mathrm{kg}$ of their weight at the moment of the first injection of females.

The fertilization process was performed according to Horvath et al. (2015) method. For each female, the stripped ova were fertilized immediately by sperms originating at least, from 3 males. The fertilized eggs were washed with a $20 \%$ sodium chloride solution $(\mathrm{NaCl})$ in order to stimulate the spermatozoa and to extend the fertilization process. Then they were washed with a clear water, this operation was repeated three times. After that, the swollen eggs of every female were held, separately, in conic incubators jars at water temperature of $24^{\circ} \mathrm{C}$. the incubation was supplied with an ascendant water flow during the egg development stages until the hatching of fry. The water flow was adjusted according to the stage of the development of the eggs to ensure sufficient supply of oxygene (Horvath et al., 2015).

In the present study, 4 artificial breeding protocols (P1, P2, P3, P4) were performed during the reproductive season. The Unfertilized ova were collected from 23 females. Their weight varied from $1.7 \mathrm{~kg}$ to $5.5 \mathrm{~kg}$. The weight of the stripped ova varied from $191 \mathrm{~g}$ to $875.6 \mathrm{~g}$.

\section{Determination of Fatty Acids Profile of The Silver Carp' Ova}

Total lipids were extracted following the protocol of Folch et al (1957). To determine the ova fatty acids profile, every sample of extracted lipids, about 2 grams, was subjected to trans-esterification. The reaction was catalyzed by $1.5 \% \mathrm{NaOH}(\mathrm{w} / \mathrm{w})$ in methanol $1: 20$ at $80^{\circ} \mathrm{C}$ during $5 \mathrm{~h}$. The resulting fatty acids methyl esters were analyzed by capillary gas chromatography (Agilent 7890 A Series GC) Tandem to mass spectrometry (MS) equipped with multimode injector and $5 \mathrm{MS}$ column (30 $\mathrm{m} \times 250 \mathrm{um} \times 0,25 \mathrm{~m}$ ) and electron impact ionization. The detection of fatty acid methyl esters profile was done using full scan mode between 35 and $500 \mathrm{~m} / \mathrm{s}$ with gain factor 5 and identification was performed using NIST 2011 MS Library and known standards. The fatty acids methyl esters composition was calculated as percentage of the total FAME presents in the sample, determined from the peak areas.

\section{Assessment of Egg Quality}

The egg quality was determined based on three viability rates (fertilization success, survival rate of embryos and survival rate of fry) assessed during the incubation process.
Fertilization success;

$$
\frac{\text { number of developing eggs }}{\text { total number of egg. } s \text { in the sample }} \times 100
$$

Survival rate of embryos;

$$
\frac{\text { number of viable embryos }}{\text { total number of embryos in the sample }} \times 100
$$

Survival rate of fry;

number of viable pre - hatchnig embryos



\section{Statistical Analysis}

The determination of the fertilization was based on the following equation given by Mansour et al. (2011). The range between the highest and lowest rates of the fertilization was approximately classified into three equal classes. This equation was used to determine weight and age class of females in order to determine their relationship to the fatty acids composition in ova.

$$
\begin{aligned}
& \text { Class limit } \\
& =\frac{\text { The highest rate of eyed stage }- \text { the lowest rate of eyed stage }}{3}
\end{aligned}
$$

Data were statistically analyzed by IBM.SPSS. Statistics software, version 23 (IBM Corporation, Somers, NY, USA). One-way ANOVA was used to analyze the effect of fatty acid composition on eggs performance. Pearson's correlation was used to determine the relationship between fatty acids content, fertilization rate and embryos survival rate.

\section{Results and Discussion}

\section{Fatty Acids Profile of the Silver Carp' Eggs}

The present study highlights the richness of silver carp 'eggs by PUFAs which is barely distinguishable from the general freshwater fish fatty acids profile (Tocher, 2003). In silver carp' eggs, the proportions of polyunsaturated (PUFA), monounsaturated (MUFA) and saturated fatty acids (SFA) were not highly different. The overall average was $33.22 \%, 29.60 \%$ and $32.44 \%$, respectively for PUFA, MUFA and SFA (Table 1). Saturated and monounsaturated fatty acids are usually catabolized for energy, long-chain polyunsaturated fatty acids accumulate in sufficient quantities in the oocytes to ensure adequate hatching and early growth and survival of the larvae (Izquierdo et al., 2001; GonzálezFélix et al., 2019). The DHA (C22:6) was the major fatty acid in the eggs of the silver carp followed by EPA (C20:5), palmitic acid C16:0 (SFA) and oleic acid C18:1 (MUFA). These findings are in concordance with previous studies performed on silver carp's tissues. For Instance, Kindong et al. (2017) found that the tissues of 
Table 1. Fatty-acid composition of total lipids extracted from silver carp' eggs. Data expressed as weight \% of total identified fatty acids and represent means \pm SD of 23 samples

\begin{tabular}{lc} 
Fatty acids & Eggs fatty acids \% \\
\hline C14:0 & $1.63 \pm 0.12$ \\
C15:0 & $0.94 \pm 0.09$ \\
C16:0 & $17.70 \pm 0.53$ \\
C17:0 $18: 0$ & $4.28 \pm 0.22$ \\
C20:0 & $8.32 \pm 0.20$ \\
C24:0 & $0.11 \pm 0.01$ \\
SFA & $0.25 \pm 0.03$ \\
C16:1 & $33.22 \pm 1.21$ \\
C17:1 & $5.37 \pm 0.16$ \\
C18:1 & $0.20 \pm 0.04$ \\
C19:1 & $21.19 \pm 1.03$ \\
C20:1 & $0.24 \pm 0.05$ \\
MUFA & $2.78 \pm 0.09$ \\
C17:3 & $29.79 \pm 1.37$ \\
C18:3ALA & $0.03 \pm 0.02$ \\
C20:5 EPA & $0.08 \pm 0.03$ \\
C20:4 AA & $10.29 \pm 0.84$ \\
C22:6 DHA & $2.57 \pm 0.24$ \\
C22:5 DPA & $21.21 \pm 1.19$ \\
PUFA & $2.76 \pm 0.29$ \\
n-3 & $36.94 \pm 2.61$ \\
n-6 & $31.57 \pm 1.009$ \\
n-3/n-6 & $5.33 \pm 0.33$ \\
\hline
\end{tabular}

this specie contain palmitic acid (C16:0), with high proportion, oleic acid (C18:1), $\alpha$-linolenic acid (C18:3), DHA and EPA. These results are different from our findings except the $\alpha$-linolenic acid (C18:3) which was found with a very small amounts in silver carp eggs than tissues. This difference could be related to the habitat changes and diet of the broodfish used for the studies. In fact, oleic acid (C18:1n-9) is produced by the desaturation of saturated fatty acids synthesized in the fish organism from energy-rich supplemented feed (e.g. Buchtová, 2011).

For instance, a study performed on egg of the chinook salmon, Oncorhynchus tshawytscha, showed that n-3 FA in total lipids for wild and cultured fish was $40,2 \%$ and $29,4 \%$, respectively. The study showed that wild fish contained higher concentration of C20:5n-3 than cultured fish (Ashton et al, 1993; Palacios et al., 2007). The eggs of walleye, Stizostedion vitreum, contain high level of DHA for both wild and domesticated fish. But the fatty acids profile differed, significantly, among the wild and the domesticated fish (Czesny and Dabrowski, 1998; Palacios et al., 2007).

In the present study, it was found that Within wthin the PUFA ${ }_{L}$ the $n-3$ series were more abundant than the $n-6$ series. The total mean was $31.57 \pm 1.01 \%$ for the $n-3$ series and $5.33 \pm 0.32 \%$ for the $n-6$ series. The overall ratio $(n-3) /(n-6)$ was $6.50 \%( \pm 0.50)$. The diet of this species may be responsible for this result. As it was demonstrated previously by other studies, silver carp feeds on phytoplankton which is well known by high concentration of n-3 fatty acids (Steffens et Wirth, 2005; Farid et al., 2017).

\section{Fatty Acids Effect on Fertilization Success, Embryos Mortality and Survival of Larvae}

The current study revealed the absence of the effect of the fatty acids content on the fertilization ratio and the survival of the embryos (using One-way ANOVA). However, the same test showed that fertilization success class is related to the levels of C14:0 and C15:0. The experiment revealed that high levels of the two fatty acids, cited bellow, belongs to eggs that had a medium fertilization success. The values were 2.14\% for C14:0 and 1.34 \% for C15:0. However, levels of fatty acid were not related to ova with high fertilization success and those of low fertilization success (Figure.1).

The association between fertilization and fatty acids in general has been well reviewed previously (McKeegan \& Sturmey, 2011; Dunning et al., 2014). Further, it was demonstrated that $n-3$ fatty acids are essential for the fertilization success in many fish species (Mukhopadhyay and Ghosh, 2003; Ovissipour and Rasco, 2011). It was found that low levels of PUFAs in Beluga's eggs (Huso huso) affects negatively the fertilization and the hatching ratios (Ovissipour and Rasco, 2011). The richness of silver carp feed by $n-3$ series is probably responsible of the absence of the variability of the fertilization success during the breeding season. In other fish species, some fatty acids varied within the breeding season, for instance in the eggs of the common snook, Centropomus undecimalis, the PUFAs changed during the spawning season and the fertilization success and larval survival rate are related to high concentration of DHA (Yanes-Roca et al., 2009). 


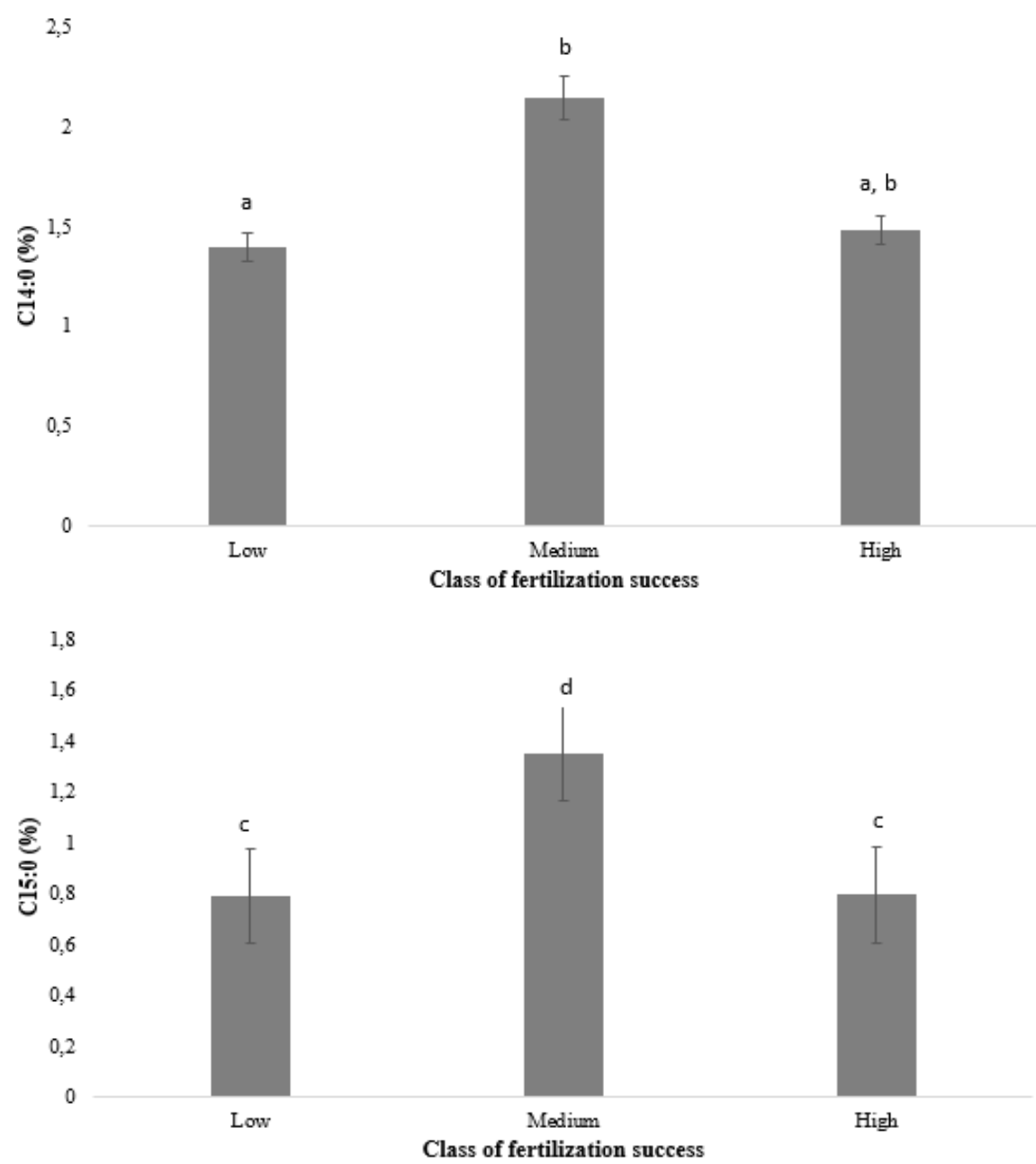

Figure 1. Variation of $\mathrm{C} 14: 0$ and $\mathrm{C} 15: 0$ in eggs according to the fertilization success. Low $<41.53 \%$; Medium $<58.28 \%$; High $>58.28 \%$; The means followed by the same letter do not show a significant difference between them.

\section{Changes of Fatty Acids Composition of Silver Carp Eggs Throughout the Breeding Season}

In the current study, the overall amount of PUFAs, MUFAs and SFA varied respectively between $37.98 \%$ and $35.31 \%, 27.73 \%$ and $31.23 \%, 34.46 \%$ and $31.89 \%$ (Table.2). On the other hand, the one-way ANOVA test revealed that the $n-3$ series didn't change during the breeding season. The overall amount varied between 29.34\% and 33.24\% (Table.2). Likewise, the C16:1 increased during the breeding season. Except the $\mathrm{C} 16: 1$, ANOVA 1 test showed that there are no changes of fatty acids profile in silver carp eggs during the breeding season. This can be due to the food availability and that silver carp is not a multi-spawner fish. In addition, no direct relationship was found between fatty acids profile of the egg and the fertilization success. This result was also found in other fish species which fatty acids remain stable during the reproductive season (captive walleye, Mejri et al., 2014; ballan wrasse, Grant et al., 2016; white trevally, Nogueira et al., 2018). However, studies performed on turbot eggs, showed that they are impacted by the progress of the spawning season; the weight of total lipid per egg fell as the spawning season progressed and there were significant increases in the levels of $18: 3 n-3,22: 4 n-6$ and 22:5n-3in the neutral lipid fraction but neutral $20: 5 n-3$ and $22: 6 n-3$ levels remained fairly constant throughout the season (McEvoy et al., 1993).

However, the study has revealed the variation of $n$ 6 series and $n-3 / n-6$ ratio throughout the breeding season $(F(3.19)=3.987, P=0.023)$ and $(F(3.19)=5.166$, $\mathrm{P}=0.009)$ respectively. A Tukey post hoc test showed that $n-6$ series were statistically lower at the P3 (4.38 \pm $0.45, P=0.041)$ compared to the end $(6.72 \pm 0.71)$ of the breeding season (P4) (Table 2). The $n-3 / n-6$ ratio was lower at the P2 $(4.93 \pm 0.19, \mathrm{P}=0.041)$ and the $\mathrm{P} 4(4.70$ $\pm 0.28, P=0.037)$ compared to the beginning $(8.21 \pm 1.15)$ of the breeding season (Table. 2).

\section{Maternal Effect on Fatty Acids Profile in Eggs}

Many studies were interested in maternal contribution on fatty acid profile in fish eggs (Bachan et al., 2012; Ulvund and Grahl-Nielsen, 1988). It was demonstrated that eggs stripped from small females, low weight and length, contained lower amounts of fatty acids than the bigger females (Ulvund and Grahl- 
Table 2. Fatty acids composition of eggs, during the breeding season. No statistical difference was detected between the means of the fatty acids during the reproductive season

\begin{tabular}{|c|c|c|c|c|}
\hline \multirow{3}{*}{ Fatty acids } & \multicolumn{4}{|c|}{ Spawning detection } \\
\hline & \multicolumn{2}{|c|}{ April } & \multicolumn{2}{|c|}{ May } \\
\hline & P1 & $\mathrm{P} 2$ & $\mathrm{P} 3$ & $\mathrm{P} 4$ \\
\hline C14:0 & $1.64 \pm 0.18$ & $1.41 \pm 0.2$ & $1.49 \pm 0.15$ & $2.01 \pm 0.41$ \\
\hline C15:0 & $0.90 \pm 0.21$ & $0.89 \pm 0.14$ & $0.91 \pm 0.12$ & $0.90 \pm 0.26$ \\
\hline C16:0 & $17.40 \pm 1.55$ & $18.69 \pm .93$ & $16.60 \pm .68$ & $18.15 \pm .80$ \\
\hline C17:0 & $3.58 \pm 0.48$ & $4.78 \pm 0.28$ & $4.19 \pm 0.52$ & $4.61 \pm 0.29$ \\
\hline C18:0 & $8.47 \pm 0.53$ & $8.4 \pm 0.36$ & $8.23 \pm 0.28$ & $8.15 \pm 0.51$ \\
\hline C20:0 & $0.14 \pm 0.03$ & $0.08 \pm 0.028$ & $0.11 \pm 0.026$ & $0.10 \pm 0.028$ \\
\hline C24:0 & $0.31 \pm 0.073$ & $0.19 \pm 0.066$ & $0.28 \pm 0.065$ & $0.16 \pm 0.070$ \\
\hline SFA & $32.51 \pm 2$ & $34.46 \pm 1.71$ & $31.89 \pm 0.76$ & $34.26 \pm 1.51$ \\
\hline C16:1 & $4.86 \pm 0.26$ & $5.23 \pm 0.20$ & $5.62 \pm 0.4$ & $5.83 \pm 0.21$ \\
\hline C17:1 & $0.24 \pm 0.109$ & $0.14 \pm 0.050$ & $0.26 \pm 0.062$ & $0.12 \pm 0.082$ \\
\hline C18:1 & $21.4 \pm 0.91$ & $22.24 \pm 0.736$ & $22.10 \pm 0.551$ & $18.57 \pm 4.699$ \\
\hline C19:1 & $0.165 \pm 0.106$ & $0.161 \pm 0.102$ & $0.358 \pm 0.114$ & $0.298 \pm 0.123$ \\
\hline C20:1 & $2.94 \pm 0.169$ & $2.43 \pm 0.149$ & $2.86 \pm 0.145$ & $2.89 \pm 0.223$ \\
\hline MUFA & $29.70 \pm 0.92$ & $30.22 \pm 0.73$ & $31.23 \pm 0.46$ & $27.73 \pm 4.36$ \\
\hline C17:3 & n.d. & $0.04 \pm 0.043$ & $0.06 \pm 0.067$ & n.d. \\
\hline $\mathrm{C} 18: 3$ & $0 \pm 0$ & $0.11 \pm 0.060$ & $0.08 \pm 0.041$ & $0.12 \pm 0.124$ \\
\hline C20:5 EPA & $9.85 \pm 0.566$ & $8.81 \pm 0.710$ & $12.71 \pm 2.969$ & $9.65 \pm 0.820$ \\
\hline C20:4 AA & $2.51 \pm 0.663$ & $2.55 \pm 0.123$ & $2.19 \pm 0.525$ & $3.10 \pm 0.489$ \\
\hline C22:6 DHA & $23.38 \pm 1.658$ & $20.40 \pm 1.332$ & $19.59 \pm 3.910$ & $21.48 \pm 1.987$ \\
\hline C22:5 DPA & $2.01 \pm 0.768$ & $3.36 \pm 0.163$ & $2.19 \pm 0.619$ & $3.61 \pm 0.272$ \\
\hline PUFA & $37.77 \pm 2.75$ & $35.31 \pm 2.31$ & $36.85 \pm 1.12$ & $37.98 \pm 7.63$ \\
\hline Total n-6 & $4.53 \pm 0.69$ & $5.92 \pm 0.27$ & $4.39 \pm 0.45$ & $6.72 \pm 0.71$ \\
\hline Total n-3 & $33.24 \pm 2.18$ & $29.34 \pm 2.089$ & $32.39 \pm 1.03$ & $31.26 \pm 2.81$ \\
\hline Total $(n-3) /(n-6)$ & $8.21 \pm 1.15$ & $4.93 \pm 0.19$ & $7.83 \pm 0.97$ & $4.71 \pm 0.34$ \\
\hline
\end{tabular}

Abbr. SFA, saturated fatty acids, MFA, monounsaturated fatty acids, PUFA, polyunsaturated fatty acids; n.d. not detectable. Data expressed as weight

$\%$ of total identified fatty acids and represent means \pm SD.

Nielsen, 1988). The present study revealed the presence of an effect of age and weight of the female on the concentration of specific fatty acids in the egg, using one-way ANOVA test. High levels of C18:0 were detected on eggs originated from females of high weight (> $4 \mathrm{~kg}$ ) and it reached $23.278 \%$ in total lipids, then followed by eggs of females with medium weight $(2.7 \mathrm{~kg}$ $<$ medium $<4 \mathrm{~kg}$ ) with an average of $22.656 \%$ in total lipids. The females with low weight (low $<2.7 \mathrm{~kg}$ ) gave eggs that contains low levels of C18:0 (16.62\% in total lipids) (Table.3). On the other hand, arachidonic acid decreased with the increase of female weight. It declines from $3.701 \%$ to $2.268 \%$, then in eggs of females with high weight this fatty acid decreased to reach $1.871 \%$. Using one-way ANOVA, the same variation was observed for the docosahexaenoic acid (C22:6), it decreased with the increase of class weight. It reached $25.158 \%, 21.23 \%$ and $15.208 \%$ for low, medium and high weight, respectively. Additionally, Pearson's test demonstrated that female's weight and length were correlated to EPA, DHA and AA levels (Table. 4).

High values of C16:1 was obtained in eggs of medium class age, whereas the youngest females gave ova with the lowest value (Figure.2). These values were $5.5 \%, 5.7 \%$ and $4.35 \%$ respectively for low, medium and high class of age. C20:5 was high in eggs of females with medium age (18.7\%) followed by eggs of older females $(10.74 \%)$ then the youngest females which contains the lowest value (9.27\%). High values of C22:6 was reached for eggs stripped from older females (25.222\%) followed by younger females (21.541\%) then eggs of females with medium age (12.17\%). Furthermore, female's age correlates significantly with $\mathrm{C} 16: 1 \quad(P=0.025 ; r=-0.458)$, $\mathrm{C} 16: 0(P=0.045 ; r=-0.422)$ and $\mathrm{C} 17: 1 \quad(P=0.007 ; r=0.544)$. Brekely et al. (2004) demonstrated that older females of the black rockfish, Sebastes melanops, gave eggs rich in lipids than younger females. Furthermore, many studies demonstrated that inter-females' differences of fatty acids in eggs is related to rearing conditions, especially the feeding of the broodstock. (Mazorra et al., 2003; Krautz et al., 2010; Asil et al., 2017).

\section{Conclusion}

Based on the obtained results, the fertilization success in silver carp eggs is related to the presence of C14:0 and C15:0. These findings could be used as a reference for the elaboration of diet that enhances the eggs quality and by this increasing the yield of the fry production of silver carp. On the other hand, the study presented the fatty acids profile of eggs of silver carp reared in Moroccan inland waters and showed that this profile remains stable during the same reproductive season. Since nutrient in eggs are transferred from the mother, the high amount of $n-3$ fatty acids in eggs reflect the richness of the fish by these high-quality fatty acids. So silver carp present a potential source of $n-3$ fatty acids for the human alimentation. 
Table 3. Variation of fatty acids according to the females' weight class

\begin{tabular}{lccc}
\hline & & Females'weight class \\
\cline { 2 - 4 } & Low & Medium & High \\
\cline { 2 - 4 } & $\leq 2.7$ & $2.7<$ & $4 \mathrm{~kg}<$ \\
$\mathrm{nyyy}$ & $\mathrm{n}=6$ & $\mathrm{n}=13$ & $\mathrm{n}=4$ \\
$\mathrm{C} 18: 1$ & $16,62 \pm 8,2^{\mathrm{a}}$ & $22,66 \pm 1.42^{\mathrm{b}}$ & $1,28 \pm 1.09$ a, b \\
$\mathrm{C} 20: 4$ & $3,701 \pm 1,05^{\mathrm{c}}$ & $2,27 \pm 0.81^{\mathrm{d}}$ & $1.25^{\mathrm{d}}$ \\
$\mathrm{C} 22: 6$ & $25,16 \pm 2.71^{\mathrm{e}}$ & $21,23 \pm 3.08^{\mathrm{e}, \mathrm{f}}$ & $15,21 \pm 10.5^{\mathrm{f}}$ \\
\hline
\end{tabular}

Data expressed as weight \% of total identified fatty acids and represent means \pm SD. The means followed by the same letter do not show a significant difference between them.

Table 4. Correlation between females' weight and length and EPA, DHA and AA in eggs. Pearson's coefficients ( $r$ ) and corresponding significance level $(\mathrm{P})$ are presented for each correlation

\begin{tabular}{lccc}
\hline & EPA & DHA & AA \\
\hline Female's weight & NS & $P=0.003 ; r=-0.588$ & $P=0.009 ; r=-0.530$ \\
Female's lenght & $P=0.013 ; r=0.508$ & $P=0.002 ; r=-0.602$ & $P=0.01 ; r=-0.525$ \\
\hline
\end{tabular}

Statistical significance was set at $\mathrm{P}<0.05$.

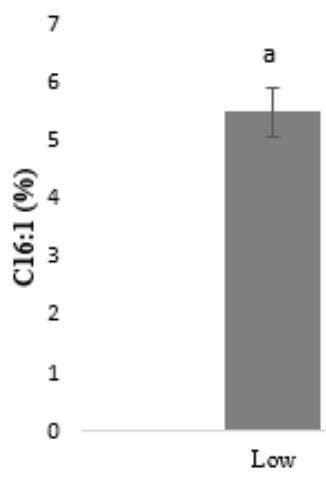

25

20

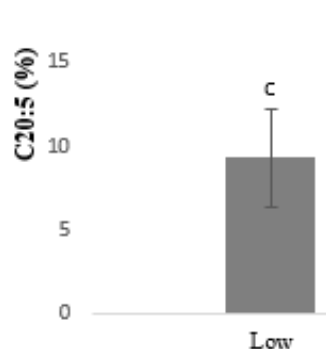

Low

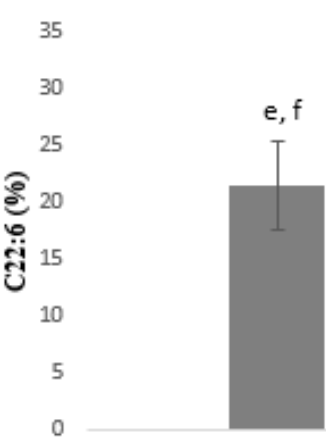

Low

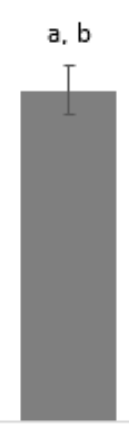

Med

Class of age

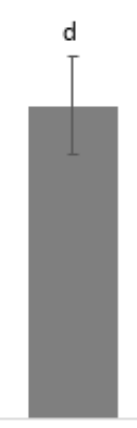

Med

Class of age

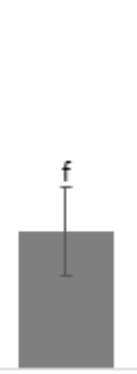

Med

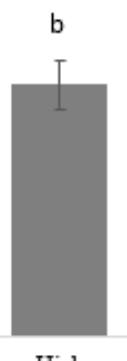

High

Class of age

Figure 2. Variation of C16:1, C20:5 and C22:6 according to the class of females' age. Low $\leq 2.7 ;$ Med 2.7<; High 4 kg <. The means followed by the same letter do not show a significant difference between them. 
Concerning the contribution of maternal traits in the fatty acids amounts in eggs, the study revealed that maternal age and weight have an important effect on their levels.

\section{Acknowledgement}

This work was realized in the framework of the International Agreement between the University of Sultan Moulay Slimane and the University of Napoli Federico II, Naples (Italy) and partially funded by a grant from CNRST-the Moroccan National Center for Scientific and Technology Research.

We thank the High Commission for Water and Forests and the Fight against Desertification in Morocco for their scientific support and all the members of the team of the fish farming station of Deroua, Beni-Mellal who contributed to this study.

\section{References}

Asil, S. M., Kenari, A. A., Miyanji, G. R., \& Van Der Kraak, G. (2017). The influence of dietary arachidonic acid on growth, reproductive performance, and fatty acid composition of ovary, egg and larvae in an anabantid model fish, Blue gourami (Trichopodus trichopterus; Pallas, 1770). Aquaculture, 476, 8-18. https://doi.org/10.1016/j.aquaculture.2017.03.048

Bachan, M. M., Fleming, I. A., \& Trippel, E. A. (2012). Maternal allocation of lipid classes and fatty acids with seasonal egg production in Atlantic cod (Gadus morhua) of wild origin. Marine biology, 159(10), 2281-2297. https://doi.org/10.1007/s00227-012-2014-6

Bacle, A., Kadri, L., Khoury, S., Ferru-Clément, R., Faivre, J. F., Cognard, C., Bescond, J., Krzesiak, A., Contzler, H., Delpech, N., Colas, J., Vandebrouck, C., Sébille, S. \& Ferreira, T. (2020). A comprehensive study of phospholipid fatty acid rearrangements in the metabolic syndrome: correlations to organ dysfunction. Disease Models \& Mechanisms. Advance online publication. https://doi.org/10.1242/dmm.043927

Baeza Ariño, R., Mazzeo, I., Vilchez Olivencia, MC., Gallego Albiach, V., Peñaranda, D., Pérez Igualada, LM., Asturiano Nemesio, JF. (2015). Relationship between sperm quality parameters and fatty acid composition of the muscle, liver and testis of European eel. Comparative Biochemistry and Physiology - Part A: Molecular and Integrative Physiology. 181:79-86. https://doi.org/10.1016/j.cbpa.2014.11.022.

Bayne, B.L. (2017). Reproduction. In Developments in Aquaculture and Fisheries Science, 41:565-701. Elsevier. https://doi.org/10.1016/B978-0-12-803472-9.00009-1

Berkeley, S. A., Chapman, C., \& Sogard, S. M. (2004). Maternal age as a determinant of larval growth and survival in a marine fish, Sebastes melanops. Ecology, 85(5), 12581264. https://doi.org/10.1890/03-0706

Bruce, M., Oyen, F., Bell, G., Asturiano, J. F., Farndale, B., Carrillo, M., Zanuy, S., Ramos, J. \& Bromage, N. (1999). Development of broodstock diets for the European sea bass (Dicentrarchus labrax) with special emphasis on the importance of n-3 and n-6 highly unsaturated fatty acid to reproductive performance. Aquaculture, 177(1-4), 8597. https://doi.org/10.1016/S0044-8486(99)00071-X
Butts, IAE., Baeza Ariño, R., Stottrup, JG., Kruger-Johnsen, M., Jacobsen, C., Pérez Igualada, LM., Asturiano Nemesio, JF. (2015). Impact of dietary fatty acids on muscle composition, liver lipids, milt composition and sperm performance in European eel. Comparative Biochemistry and Physiology - Part A: Molecular and Integrative Physiology. 183 :87-96. https://doi:10.1016/j.cbpa.2015.01.015

Castro, L. R., Claramunt, G., González, H. E., Krautz, M. C., Llanos-Rivera, A., Méndez, J., Schneider, W. \& Soto, S. (2010). Fatty acids in eggs of anchoveta Engraulis ringens during two contrasting winter spawning seasons. Marine Ecology Progress Series, 420, 193-205. https://doi.org/10.3354/meps08819

Clevestam, PD., Ogonowski, M., Sjoberg, NB., Wickstrom, H. (2011). Too short to spawn? Implications of small body size and swimming distance on successful migration and maturation of the European eel Anguilla anguilla. Journal of Fish Biology, 78:1073-1089 https://doi.org/10.1111/j.1095-8649.2011.02920.x

Czesny, S., \& Dabrowski, K. (1998). The effect of egg fatty acid concentrations on embryo viability in wild and domesticated walleye (Stizostedion vitreum). Aquatic Living Resources, 11(6), 371-378. https://doi.org/10.1016/S0990-7440(99)80002-3

da Silva, F. F., Jacobsen, C., Kjørsvik, E., Støttrup, J. G., \& Tomkiewicz, J. (2018). Oocyte and egg quality indicators in European eel: Lipid droplet coalescence and fatty acid composition. Aquaculture, 496, 30-38. https://doi.org/10.1016/j.aquaculture.2018.07.008

Dunning, K. R., Russell, D. L., \& Robker, R. L. (2014). Lipids and oocyte developmental competence: the role of fatty acids and $\beta$-oxidation. Reproduction, 148(1), R15R27. https://doi.org/10.1530/REP-13-0251

Emerenciano, M., Cuzon, G., Arévalo, M., \& Gaxiola, G. (2014). Biofloc technology in intensive broodstock farming of the pink shrimp Farfantepenaeus duorarum: spawning performance, biochemical composition and fatty acid profile of eggs. Aquaculture Research, 45(10), 17131726. https://doi.org/10.1111/are.12117

Folch, J., Lees, M., \& Stanley, G. S. (1957). A simple method for the isolation and purification of total lipides from animal tissues. Journal of biological chemistry, 226(1), 497-509. https://www.jbc.org/content/226/1/497.full.pdf

Farid, S., Ouizgane, A., Droussi, M., \& Hasnaoui, M. (2017). Evolution des paramètres zootechniques de la carpe argentée (Hypophthalmichthys molitrix) élevée sous climat semi-aride a la station de pisciculture Deroua, Maroc. Journal of Water and Environmental Sciences, 1, 115-122.

https://revues.imist.ma/index.php?journal=jwes\&page =article\&op=view\&path\%5B\%5D=8650\&path\%5B\%5D= 4947

Furuita, H., Hori, K., Sugita, T., \& Yamamoto, T. (2007). Effect of $n-3$ and $n-6$ fatty acids in broodstock diet on reproduction and fatty acid composition of broodstock and eggs in the Japanese eel Anguilla japonica. Aquaculture, 267(1-4), 55-61. https://doi.org/10.1016/j.aquaculture.2007.01.039

González-Félix, M. L., Perez-Velazquez, M., \& CañedoOrihuela, H. (2019). Seasonal changes in gonad maturity, proximate and fatty acid composition of Limbaugh's damselfish, Chromis limbaughi Greenfield \& Woods, 1980 (Pisces: Pomacentridae). Archives of Biological 
Sciences, 71(4),

755-765. https://doi.org/10.2298/ABS190613058G

Grant, B., Davie, A., Taggart, J. B., Selly, S. L., Picchi, N., Bradley, C., Prodohl, P., Leclercq, E.\& Migaud, H. (2016). Seasonal changes in broodstock spawning performance and egg quality in ballan wrasse (Labrus bergy/ta). Aquaculture, 464, 505-514.

https://doi.org/10.1016/j.aquaculture.2016.07.027

Grote, B., Ekau, W., Stenevik, E. K., Clemmesen, C., Verheye, H. M., Lipinski, M. R., and Hagen, W. (2012). Characteristics of survivors: growth and nutritional condition of early stages of the hake species Merluccius paradoxus and $M$. capensis in the southern Benguela ecosystem. - ICES Journal of Marine Science, 69: 553-562. https://doi.org/10.1093/icesjms/fss020

Henrotte, E., Mandiki, R. S., Prudencio, A. T., Vandecan, M., Mélard, C., \& Kestemont, P. (2010). Egg and larval quality, and egg fatty acid composition of Eurasian perch breeders (Perca fluviatilis) fed different dietary DHA/EPA/AA ratios. Aquaculture Research, 41(9), e53e61. https://doi.org/10.1111/j.1365-2109.2009.02455.x

Horváth, L., Tamás, G., Coche, A. G., Kovács, E., Moth-Poulsen, T., \& Woynarovich, A. (2015). Training manual on the artificial propagation of carps. A handout for on-farm training workshops on artificial propagation of common carp and Chinese major carps in Central and Eastern Europe, the Caucasus and Central Asia. FAO. https://agris.fao.org/agrissearch/search.do?recordID=XF2017000000

Izquierdo, M. S., Fernandez-Palacios, H., \& Tacon, A. G. J. (2001). Effect of broodstock nutrition on reproductive performance of fish. Aquaculture, 197(1-4), 25-42. https://doi.org/10.1016/S0044-8486(01)00581-6

Jaya-Ram, A., Kuah, M. K., Lim, P. S., Kolkovski, S., \& Shu-Chien, A. C. (2008). Influence of dietary HUFA levels on reproductive performance, tissue fatty acid profile and desaturase and elongase mRNAs expression in female zebrafish Danio rerio. Aquaculture, 277(3-4), 275-281. https://doi.org/10.1016/j.aquaculture.2008.02.027

Kindong, R., Nagarajan, P., Apraku, A., Dai, X., Gao, C., \& Muthulingam, M. (2017). Nutrients Quality and Chemical Composition of the Silver Carp (Hypophthalmichthys molitrix) from Lake Dianshan, Shanghai, China. Journal of Fisheries and Aquatic Science, 12, 226-232. https://doi.org/10.1016/j.ejbas.2017.10.001

Krautz, M. C., Vásquez, S., Castro, L. R., González, M., LlanosRivera, A., \& Pantoja, S. (2010). Changes in metabolic substrates during early development in anchoveta Engraulis ringens (Jenyns 1842) in the Humboldt Current. Marine biology, 157(5), 1137-1149. https://doi.org/10.1007/s00227-010-1395-7

Laamiri, M. B. (2014). Opportunités de développement de la pêche et de la pisciculture continentales au Maroc. University of MOHAMMED V.

Lanes, C. F. C., Bizuayehu, T. T., Bolla, S., Martins, C., de Oliveira Fernandes, J. M., Bianchini, A., Kiron, V. \& Babiak, I. (2012). Biochemical composition and performance of Atlantic cod (Gadus morhua L.) eggs and larvae obtained from farmed and wild broodstocks. Aquaculture, 324, 267-275.

https://doi.org/10.1016/j.aquaculture.2011.10.036

McKeegan, P. J., \& Sturmey, R. G. (2011). The role of fatty acids in oocyte and early embryo development. Reproduction, Fertility and Development, 24(1), 59-67. https://doi.org/10.1071/RD11907
Mansour, N., Lahnsteiner, F., McNiven, M. A., Richardson, G. F., \& Pelletier, C. S. (2011). Relationship between fertility and fatty acid profile of sperm and eggs in Arctic char, Salvelinus alpinus. Aquaculture, 318(3-4), 371-378. https://doi.org/10.1016/j.aquaculture.2011.05.023

Mazorra, C., Bruce, M., Bell, J. G., Davie, A., Alorend, E., Jordan, N., Rees, J., Papanikos, N., Porter, M. \& Bromage, N. (2003). Dietary lipid enhancement of broodstock reproductive performance and egg and larval quality in Atlantic halibut (Hippoglossus hippoglossus). Aquaculture, 227(1-4), 21-33.

ttps://doi.org/10.1016/S0044-8486(03)00493-9

Mejri, S., Audet, C., Vandenberg, G. W., Parrish, C. C., \& Tremblay, R. (2014). Biochemical egg quality in a captive walleye (Sander vitreus) broodstock population relative to ovulation timing following hormonal treatment. Aquaculture, 431, 99-106.

ttps://doi.org/10.1016/j.aquaculture.2014.03.022

Mukhopadhyay, T., \& Ghosh, S. (2003). Lipid profile and fatty acid composition in eggs of common carp (Cyprinus carpio). Journal of Oleo Science,52(8), 439-442. https://doi.org/10.5650/jos.52.439

Nogueira, N., Ferreira, M., Cordeiro, N., \& Canada, P. (2018). Quality parameters of wild white trevally (Pseudocaranx dentex) natural spawn kept in captivity. Aquaculture, 495, 68-77.

ttps://doi.org/10.1016/j.aquaculture.2018.05.023

Nowosad, J., Kucharczyk, D., Łuczyńska, J., Targońska, K., Czarkowski, T. K., Biłas, M.,

Krejszeff, S., Horváth, L.\& Müller, T. (2015). Changes in European eel ovary development and body and ovary chemistry during stimulated maturation under controlled conditions: preliminary data. Aquaculture International, 23, 13-27. https://doi.org/10.1007/s10499-014-9794-2

Ovissipour, M., \& Rasco, B. (2011). Fatty acid and amino acid profiles of domestic and wild beluga (Huso huso) roe and impact on fertilization ratio. Journal of Aquaculture Research \& Development, 2(113), 10-4172. https://doi.org/ 10.4172/2155-9546.1000113

Palacios, E., Racotta, I. S., Aparicio, B., Arjona, O., \& MartínezPalacios, C. A. (2007). Lipid classes and fatty acids during embryogenesis of captive and wild silverside (Chirostoma estor estor) from Pátzcuaro Lake. Fish physiology and biochemistry, 33(1), 81-91. https://doi.org/10.1007/s10695-006-9119-0

Pickova, J., Dutta, P. C., Larsson, P. O., \& Kiessling, A. (1997). Early embryonic cleavage pattern, hatching success, and egg-lipid fatty acid composition: comparison between two cod (Gadus morhua) stocks. Canadian Journal of Fisheries and Aquatic Sciences, 54(10), 2410-2416. https://doi.org/10.1139/f97-148

Salze, G., Tocher, D. R., Roy, W. J., \& Robertson, D. A. (2005). Egg quality determinants in cod (Gadus morhua L.): egg performance and lipids in eggs from farmed and wild broodstock. Aquaculture Research, 36(15), 1488-1499. https://doi.org/10.1111/j.1365-2109.2005.01367.x

Seaborn, G. T., Smith, T. I., Denson, M. R., Walker, A. B., \& Berlinsky, D. L. (2009). Comparative fatty acid composition of eggs from wild and captive black sea bass, Centropristis striata L. Aquaculture research, 40(6), 656-668. https://doi.org/10.1111/j.1365-2109.2008.02141.x

Steffens, W., \& Wirth, M. (2005). Freshwater fish-an important source of $n-3$ polyunsaturated fatty acids: a 
review. Fisheries \& Aquatic Life, 13(1), 5-16. http://www.fal.infish.com.pl/index.php/FisheriesAndAq uaticLife/article/view/156/156

Taşbozan, O., \& Gökçe, M. A. (2017). Fatty acids in fish. Fatty Acids, 1, 143-159. https://doi.org/ 10.5772/68048

Tocher, D. R. (2003). Metabolism and functions of lipids and fatty acids in teleost fish. Reviews in fisheries science, 11(2), 107-184.

https://doi.org/10.1080/713610925

Ulvund, K. A., \& Grahl-Nielsen, O. (1988). Fatty acid composition in eggs of Atlantic cod (Gadus morhua). Canadian Journal of Fisheries and Aquatic Sciences, 45(5), 898-901. https://doi.org/10.1139/f88108

Wiegand, M. D. (1996). Composition, accumulation and utilization of yolk lipids in teleost fish. Reviews in fish biology and fisheries, 6(3), 259-286. https://doi.org/10.1007/BF00122583

Yanes-Roca, C., Rhody, N., Nystrom, M., \& Main, K. L. (2009). Effects of fatty acid composition and spawning season patterns on egg quality and larval survival in common snook (Centropomus undecimalis). Aquaculture, 287(34), 335-340.

https://doi.org/10.1016/j.aquaculture.2008.10.043

Ye, H., Xu, M., Liu, Q., Sun, Z., Zou, C., Chen, L., Su, N \& Ye, C. (2019). Effects of replacing fish meal with soybean meal on growth performance, feed utilization and physiological status of juvenile obscure puffer, Takifugu obscurus. Comparative Biochemistry and Physiology Part C: Toxicology \& Pharmacology, 216, 75-81. https://doi.org/10.1016/j.cbpc.2018.11.006 